\title{
A lack of association between the $C R P$ rs2794520 polymorphism and coronary artery disease
}

\author{
JIANGFANG LIAN $^{1 *}$, JUNXING LI $^{1,2^{*}}$, DONGJUN DAI ${ }^{2 *}$, PEILIANG FANG $^{1,2}$, \\ JIANQING ZHOU ${ }^{1}$ and SHIWEI DUAN ${ }^{2}$ \\ ${ }^{1}$ Ningbo Medical Center, Lihuili Hospital; ${ }^{2}$ Zhejiang Provincial Key Laboratory of Pathophysiology, \\ School of Medicine, Ningbo University, Ningbo, Zhejiang 315000, P.R. China
}

Received September 2, 2014; Accepted October 29, 2014

DOI: $10.3892 /$ br.2014.384

\begin{abstract}
Coronary artery disease (CAD) is mainly caused by atherosclerosis, which is closely associated with the C-reactive protein $(C R P)$, a systemic inflammatory mediator. The aim of the present study was to examine whether the CRP rs2794520 polymorphism played a role in the risk of CAD. A total of 459 CAD patients and 432 non-CAD controls were recruited in the case-control study. Genotyping was performed on the SEQUENOM $^{\circledR}$ Mass-ARRAY iPLEX ${ }^{\circledR}$ platform according to the manufacturer's instructions. The results showed that CRP rs2794520 was not associated with CAD. A further breakdown analysis by age or gender also indicated a lack of association between rs2794520 and CAD. In addition, the CRP rs2794520 polymorphism was not associated with the severity of CAD, which was represented by the number of coronary arteries with stenosis. In conclusion, there was no contribution of the CRP rs2794520 polymorphism to the risk of CAD.
\end{abstract}

\section{Introduction}

Coronary artery disease (CAD) is characterized by the narrowed or blocked coronary arteries that can cause a lack of myocardial oxygen supply. CAD is the main cause of human fatalities worldwide (1). CAD is a complex disorder contributed by environmental and genetic factors (2). C-reactive protein (CRP) is a widely used inflammatory factor (3) in the detection

Correspondence to: Dr Jianqing Zhou, Ningbo Medical Center, Lihuili Hospital, Ningbo University, 57 Xingning Road, Ningbo, Zhejiang 315000, P.R. China

E-mail: hjmpin@163.com

Professor Shiwei Duan, Zhejiang Provincial Key Laboratory of Pathophysiology, School of Medicine, Ningbo University, Ningbo, 818 Fenghua Road, Zhejiang 315000, P.R. China

E-mail: duanshiwei@nbu.edu.cn

\section{${ }^{*}$ Contributed equally}

Key words: C-reactive protein, coronary artery disease, rs2794520, no association of systemic inflammation diseases, such as atherosclerosis (4), which is an inflammation process closely linked to CAD $(5,6)$. The circulating CRP level was found to be significantly associated with the risk of CAD (7-10). Aggregated $C$ reactive protein was found to bind to low-density lipoproteins and very low-density lipoprotein (11) in the atherosclerotic plaques (12).

Recent genetic and genome-wide association studies have identified a number of genetic loci that are associated with CRP levels (9,13-16). Approximately $40 \%$ of CRP level variation was determined by genetic factors (10), including the $C R P$ rs2794520 polymorphism, which was one of most significant markers in the meta-analysis of the genome-wide association studies among >80,000 European subjects (9).

In association with the previous studies, we hypothesized that the $C R P$ rs 2794520 polymorphism may influence the risk of CAD. Thus, a case control study was performed to assess the contribution of the CRP rs 2794520 polymorphism to CAD in the Han Chinese population.

\section{Materials and methods}

Study population. A total of 891 unrelated individuals were carefully selected, which included 459 CAD patients (males, 69.9\%; age, 59.7 \pm 9.48 years; diabetes mellitus, $22.1 \%$; hypertension, $60.3 \%$; body mass, $23.4 \pm 3.4 \mathrm{~kg} / \mathrm{m}^{2}$; and smokers, $44.5 \%$ ) and 432 non-CAD patients (males, $54.4 \%$; age, $59.7 \pm 9.48$ years; diabetes mellitus, $11.5 \%$; hypertension, $49.3 \%$; body mass, $23.3 \pm 3.4 \mathrm{~kg} / \mathrm{m}^{2}$; and smokers, $31.7 \%$ ). All were Han Chinese residents of Ningbo city in Eastern China. The standards required were that the involved CAD patients should have one or more major coronary arteries with a diameter stenosis $\geq 50 \%$, or had a history of a coronary artery bypass surgery or prior angioplasty. The non-CAD patients were diagnosed with a diameter stenosis $<50 \%$ of the major coronary arteries and without any atherosclerotic vascular disease. The diagnosis was made by at least two cardiologists (JZ and JL). All the samples were recruited between May 2008 and April 2014 from Ningbo Lihuili Hospital (Ningbo, China). Blood samples were collected in $3.2 \%$ citrate sodium-treated tubes and subsequently stored at $-80^{\circ} \mathrm{C}$. The protocol was approved by the Ethical Committee of Ningbo Lihuili Hospital and all the involved individuals provided signed informed consent. 
Table I. Comparison of the genotype and allele frequencies between the cases and controls by gender.

\begin{tabular}{|c|c|c|c|c|c|c|c|c|c|c|c|}
\hline \multirow[b]{2}{*}{ Subjects } & \multirow{2}{*}{$\begin{array}{l}\text { rs2794520 } \\
\operatorname{group}(n)\end{array}$} & \multirow[b]{2}{*}{$\begin{array}{c}\text { Genotype, counts } \\
\text { TT/TC/CC }\end{array}$} & \multirow{2}{*}{\multicolumn{2}{|c|}{$\begin{array}{r}\text { P-value } \\
x^{2} \quad(\mathrm{df}=2)\end{array}$}} & \multirow[b]{2}{*}{ HWE } & \multicolumn{2}{|c|}{ Allele, counts } & \multirow[b]{2}{*}{$\chi^{2}$} & \multirow{2}{*}{$\begin{array}{l}\text { P-value } \\
(\mathrm{df}=1)\end{array}$} & \multirow[b]{2}{*}{ OR $(95 \% \mathrm{CI})$} & \multirow[b]{2}{*}{ Power } \\
\hline & & & & & & $\mathrm{T}$ & $\mathrm{C}$ & & & & \\
\hline \multirow[t]{2}{*}{ All } & CAD case $(459)$ & $146 / 230 / 83$ & & & 0.70 & 522 & 396 & & & & \\
\hline & Non-CAD controls (432) & $153 / 217 / 62$ & 2.77 & 0.25 & 0.31 & 523 & 341 & 2.47 & 0.12 & $1.16(0.96-1.41)$ & 0.474 \\
\hline \multirow[t]{2}{*}{ Male } & CAD case $(321)$ & $100 / 159 / 62$ & & & 1.00 & 359 & 283 & & & & \\
\hline & Non-CAD controls (235) & $81 / 124 / 30$ & 4.25 & 0.12 & 0.13 & 286 & 184 & 2.71 & 0.10 & $1.23(0.96-1.56)$ & 0.314 \\
\hline \multirow[t]{2}{*}{ Female } & CAD case $(138)$ & $46 / 71 / 21$ & & & 0.60 & 163 & 113 & & & & \\
\hline & Non-CAD controls (197) & $72 / 93 / 32$ & 0.59 & 0.74 & 0.88 & 237 & 157 & 0.08 & 0.78 & $1.05(0.76-1.43)$ & 0.209 \\
\hline
\end{tabular}

df, degrees of freedom; HWE, Hardy-Weinberg equilibrium; OR, odds ratio; CI, confidence interval; CAD, coronary artery disease.

Table II. Comparison of the genotype and allele frequencies between the cases and controls by age.

\begin{tabular}{|c|c|c|c|c|c|c|c|c|c|c|}
\hline Age, years & $\begin{array}{c}\text { rs } 2794520 \\
\text { group, n }\end{array}$ & $\begin{array}{c}\text { Genotype, } \\
\text { counts } \\
\text { TT/TC/CC }\end{array}$ & $\chi^{2}$ & $\begin{array}{l}\text { P-value } \\
(\mathrm{df}=2)\end{array}$ & HWE & $\begin{array}{c}\text { Allele, } \\
\text { counts } \\
\text { T/C }\end{array}$ & $\chi^{2}$ & $\begin{array}{c}\text { P-value } \\
(\mathrm{df}=1)\end{array}$ & OR $(95 \% \mathrm{CI})$ & Power \\
\hline \multirow[t]{2}{*}{$55 \leq$} & CAD case $(115)$ & $40 / 61 / 14$ & & & 0.24 & $141 / 89$ & & & & \\
\hline & Non-CAD controls (159) & $57 / 81 / 21$ & 0.13 & 0.94 & 0.41 & $195 / 123$ & 0.000015 & 1.00 & $1.00(0.71-1.42)$ & 0.179 \\
\hline \multirow[t]{2}{*}{$55-65$} & CAD case $(162)$ & $49 / 83 / 30$ & & & 0.75 & $181 / 143$ & & & & \\
\hline & Non-CAD controls (166) & $59 / 86 / 21$ & 2.52 & 0.28 & 0.25 & $204 / 128$ & 2.11 & 0.15 & $1.26(0.92-1.72)$ & 0.209 \\
\hline \multirow[t]{2}{*}{$\geq 65$} & CAD case $(182)$ & $57 / 86 / 39$ & & & 0.55 & $200 / 164$ & & & & \\
\hline & Non-CAD controls (107) & $37 / 50 / 20$ & 0.47 & 0.79 & 0.69 & $124 / 90$ & 0.49 & 0.48 & $1.13(0.80-1.59)$ & 0.182 \\
\hline
\end{tabular}

df, degrees of freedom; HWE, Hardy-Weinberg equilibrium; OR, odds ratio; CI, confidence interval; CAD, coronary artery disease.

Single-nucleotide polymorphism (SNP) genotyping. The genomic DNA was isolated from peripheral blood lymphocytes using a conventional phenol/chloroform method, and subsequently DNA was quantified using the PicoGreen ${ }^{\circledR}$ double strand (dsDNA) DNA Quantification kit (Molecular Probes, Inc., Eugene, OR, USA). Amplification of the genomic DNA was performed on the ABI Gene Amp ${ }^{\circledR}$ PCR System 9700 Dual 384-Well Sample Block Module (Applied Biosystems, Foster City, CA, USA) for the quantitative polymerase chain reaction (qPCR) analysis. The surrounding DNA sequence of the tested polymorphism was downloaded from the NCBI dbSNP. Online program (http://www6.appliedbiosystems. com/support/techtools/calc/) was used to design the primers. The sequences of the primers are as follows: Forward, 5'-GCGGGCAGGGCGGCCTGTGTGTATGAAGGGCAT AGGAC-3'; and 5'-GATTACCGCTGTGTGTATGAAGGG CATAGGAT-3'; and reverse, 5'-CAGGCCTCATTCAGTGTG GACC-3'. PCR amplification procedures consisted of an initial denaturation at $95^{\circ} \mathrm{C}$ for $30 \mathrm{sec}$ to activate the enzyme activity, a 40 -cycle denaturation $\left(95^{\circ} \mathrm{C}\right.$ for $30 \mathrm{sec}$, annealing stage at $59^{\circ} \mathrm{C}$ for $30 \mathrm{sec}$, and an extension at $72^{\circ} \mathrm{C}$ for another $30 \mathrm{sec}$ ), and a final extension for $5 \mathrm{~min}$ at $72^{\circ} \mathrm{C}$. The amplified DNA was held at $4^{\circ} \mathrm{C}$. DNA amplification for genotyping was performed on the SEQUENOM ${ }^{\circledR}$ Mass-ARRAY iPLEX ${ }^{\circledR}$ platform according to the manufacturer's instructions (17).
Data analysis. Arlequin program (version 3.5) was used to estimate the Hardy-Weinberg equilibrium (HWE) (18). Clump 16 software with 10,000 Monte Carlo simulations was used to compare the frequency of the genotype and allele between cases and controls (19). Odd ratio (OR) with $95 \%$ confidential interval (CI) was calculated using an online program (http://faculty.vassar.edu/lowry/odds $2 \times 2 . h t m l)$. The power of the study was assessed by Power and Sample Size Calculation software (v3.0.43) (20). $\chi^{2}$ analysis was used to compare the severity of CAD and the rs2794520 polymorphism (21). A two-sided P-value $<0.05$ was considered to indicate a statistically significant difference.

\section{Results}

Association between the SNP and CAD. In the present study, no significant association was found between rs2794520 and CAD (P=0.12; OR, 1.16; 95\% CI, 0.96-1.41; Table I). As gender and age are two important factors in the risk of CAD, a subgroup analyses was further performed by age or gender; however, no positive results were revealed in all the tests ( $P>0.05$; Tables I and II). Additional subgroup analysis by age and gender showed a negative result in rs2794520 with CAD (P>0.05; Table III). Under the dominant model, a significant result occurred between male CAD patients and controls 


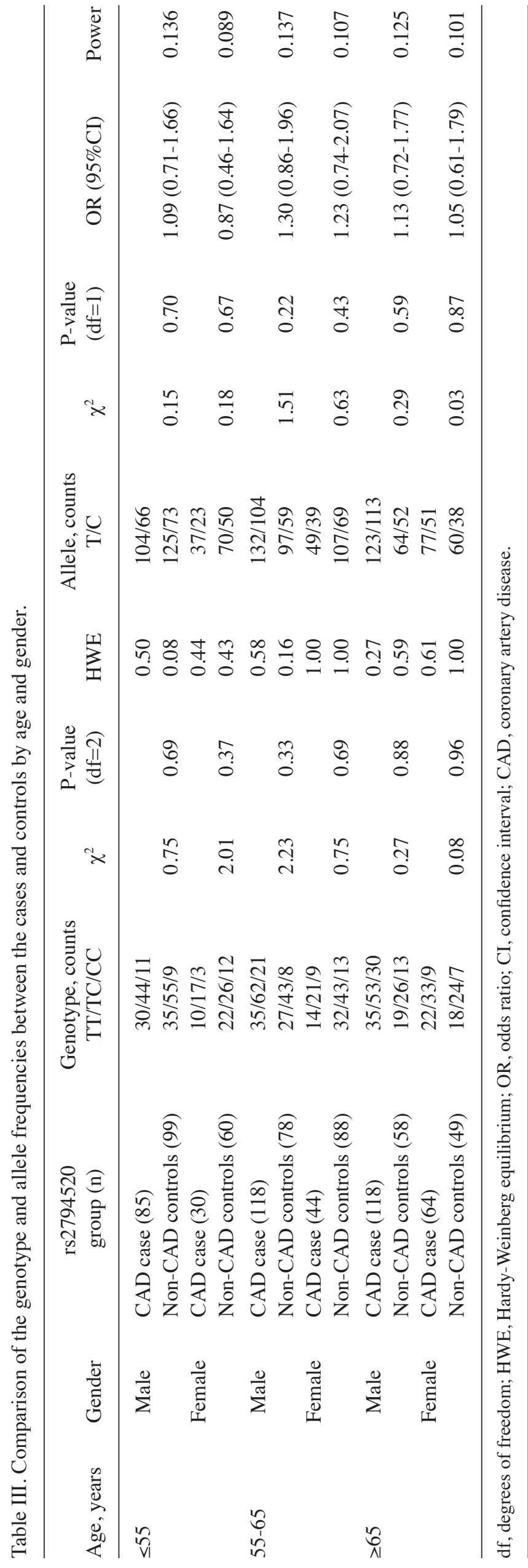

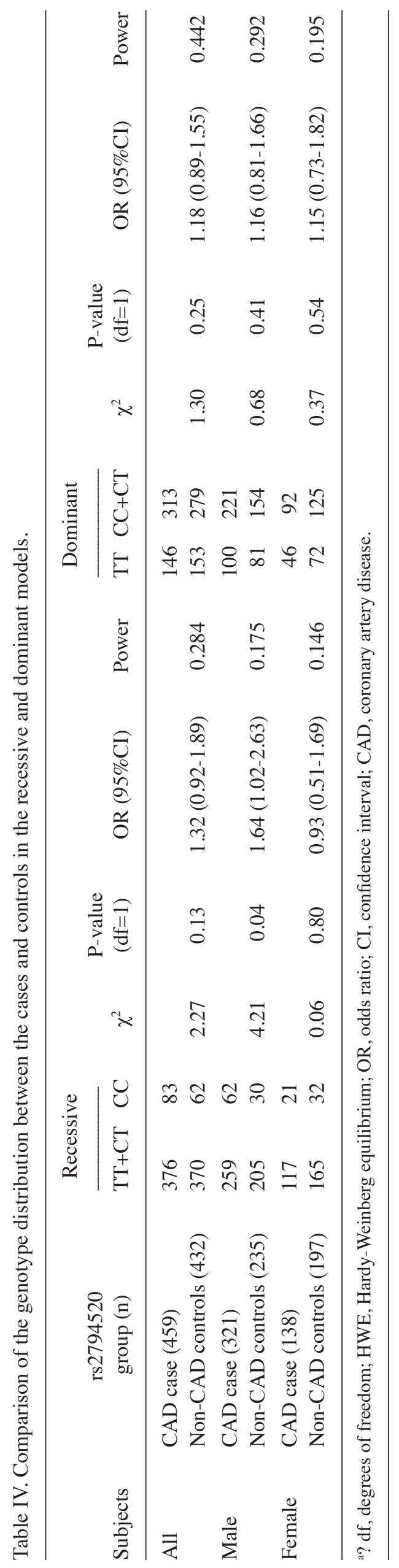


Table V. Comparison of the genotype and allele frequencies between rs2794520 and the severity of CAD patients.

\begin{tabular}{lcccccrr} 
Group & $\begin{array}{c}\text { rs2794520 } \\
\text { case, } n\end{array}$ & $\begin{array}{c}\text { Genotype, counts } \\
\text { TT/TC/CC }\end{array}$ & $\chi^{2}$ & $\begin{array}{c}\text { P-value } \\
(\mathrm{df}=4)\end{array}$ & $\begin{array}{c}\text { Allele, counts } \\
\text { T/C }\end{array}$ & $\begin{array}{c}\chi^{2} \\
(\mathrm{df}=2)\end{array}$ \\
\hline Single-vessel disease & 240 & $76 / 123 / 41$ & & & $275 / 205$ & & \\
Double-vessel disease & 110 & $36 / 57 / 17$ & & & $129 / 91$ & & \\
Triple-vessel disease & 109 & $34 / 50 / 25$ & 2.53 & 0.64 & $118 / 100$ & 0.98 & 0.61 \\
\hline
\end{tabular}

df, degrees of freedom; CAD, coronary artery disease.

( $\mathrm{P}=0.04$; OR, 1.64; 95\% CI, 1.02-2.63; Table IV), although the significance was not retained following the correction by the number of statistical tests. No significant association was found for the other genotype analyses (Table IV). The power of each analysis in the study was also calculated (Tables I-IV). These results showed that a moderate power existed in the current association test, indicating that the negative association in the study may be due to a lack of power (power=0.474; Table I). Future study or meta-analysis are required to establish the link of this polymorphism to CAD.

In addition, the association between the severity of CAD and the rs 2794520 polymorphism was also examined. All the cases were divided into three groups based on the number of major coronary artery with stenosis $\geq 50 \%$. The correlation test revealed no significant association between the severity of CAD and rs2794520 ( $\mathrm{P}=0.61$; Table IV).

\section{Discussion}

CAD has become the leading cause of fatalities in developed and developing countries. The plasma cardiac troponin I (cTnI) level was regarded as a gold standard for the diagnosis of acute myocardial infarction (AMI) worldwide (22). However, the rise of the plasma cTnI level comes after 4-6 $\mathrm{h}$ when the clinical events occurred, and this may delay the diagnosis (23). CRP levels had higher sensitivity to cardiovascular events compared to cTnI (24). Increased concentrations of plasma CRP have been found in patients with unstable angina (25). The elevation of CRP was found at the time of hospital admission in patients with myocardial infarction (MI) and history of unstable angina (24). The level of CRP was able to predict cardiovascular events in the healthy population and CAD patients $(26,27)$. A study with 911 typical exertional angina patients indicated that increased CRP levels had a positive correlation with the CAD risk (28). Additionally, a number of studies identified CRP polymorphisms as reliable biomarkers of CAD (9). A case-control study indicated that there is a significant association between the CRP $1059 \mathrm{G} / \mathrm{C}$ polymorphism (rs1800947) and AMI in Italian population (29). In the present study, a case-control study was performed that involved 459 CAD patients and 432 non-CAD patients to assess the association between $C R P$ rs 2794520 and CAD risks.

There was no association between rs2794520 and CAD $(\mathrm{P}=0.12)$. As gender and age are two well-known factors that contribute to the CAD risk (30), subgroup analyses were performed by stratifying the samples into gender and age groups. However, there was no association between the age and gender groups $(\mathrm{P}>0.05)$. Additionally, the subgroup analyses were performed by different genetic models that comprised of dominant and recessive models. A close significant result was found in the dominant model between male CAD patients and controls $(\mathrm{P}=0.04)$; however, possible multiple testing may exist in the analysis, and therefore, this result may not be considered significant. Other significant associations based on the genetic models in all the stratifications did not occur $(\mathrm{P}>0.05)$.

There were certain limitations in the present study. Firstly, the samples of the study were relatively small, and the power was 0.474 in the association between rs 2794520 and CAD, which may influence the results of the study. Therefore, studies with larger-scale samples and stronger power are required in future research to confirm the current findings. Secondly, CAD is a complex disease that environmental and genetic status may alter the results of the study, although the cases and controls in the present study were carefully selected with the help of multiple professional doctors, any hidden factors that may influence the results of the current study could not be excluded. More carefully and precisely designed studies are required to strengthen the results of the study. Thirdly, there are 2,587 polymorphisms in the $C R P$ based on the information in the dbSNP in PubMed. The present study only focused on one polymorphism that could not represent the whole contribution of $C R P$ to CAD. Other $C R P$ polymorphisms, such as $C R P$ $1059 \mathrm{G} / \mathrm{C}$ (rs1800947), were previously found to be associated with the risk of CAD (29). Examining more $C R P$ polymorphisms is required to assess their contribution to CAD.

In conclusion, the present study showed that the $C R P$ rs2794520 polymorphism had no association with the risk of CAD in the Han Chinese population. Studies with different populations and stronger power are required to further confirm the findings of the study.

\section{Acknowledgements}

The present study was supported by the grants from the National Natural Science Foundation of China (nos. 31100919, 30772155 and 81371469), Natural Science Foundation of Zhejiang Province (no. LR13H020003), K. C. Wong Magna Fund in Ningbo University, Zhejiang provincial Program for the Cultivation of High 1 level Innovative Health Talents, Natural Science Foundation of Zhejiang Province (no. Y206608), the Scientific Innovation Team Project of Ningbo (no. 2011B82014), and the Youth and Doctor Foundation of Ningbo (no. 2005A610016). 


\section{References}

1. Peng P,Lian J,Huang RS, et al: Meta-analyses of KIF6 Trp719Arg in coronary heart disease and statin therapeutic effect. PLoS One 7: e50126, 2012.

2. Zheng YY, Xie X, Ma YT, et al: A novel polymorphism $(901 \mathrm{G}>\mathrm{a})$ of $\mathrm{C} 512$ gene is associated with coronary artery disease in Chinese Han and Uyghur population. Lipids Health Dis 12: 139, 2013.

3. C Reactive Protein Coronary Heart Disease Genetics Collaboration (CCGC); Wensley F, Gao P, et al: Association between $\mathrm{C}$ reactive protein and coronary heart disease: mendelian randomisation analysis based on individual participant data. BMJ 342: d548, 2011.

4. Huang CC, Chung CM, Leu HB, et al: Genetic variation in $\mathrm{C}$-reactive protein in ethnic Chinese population in Taiwan. Eur J Clin Invest 43: 449-456, 2013.

5. Mendel I, Feige E, Yacov N, et al: VB-201, an oxidized phospholipid small molecule, inhibits CD14- and toll-like receptor-2-dependent innate cell activation and constrains atherosclerosis. Clin Exp Immunol 175: 126-137, 2014.

6. Polfus LM, Smith JA, Shimmin LC, et al: Genome-wide association study of gene by smoking interactions in coronary artery calcification. PLoS One 8: e74642, 2013.

7. van Wijk DF, Boekholdt SM, Wareham NJ, et al: C-reactive protein, fatal and nonfatal coronary artery disease, stroke, and peripheral artery disease in the prospective EPIC-Norfolk cohort study. Arterioscler Thromb Vasc Biol 33: 2888-2894, 2013.

8. Puri R, Nissen SE, Libby $\mathrm{P}$, et al: C-reactive protein, but not low-density lipoprotein cholesterol levels, associate with coronary atheroma regression and cardiovascular events after maximally intensive statin therapy. Circulation 128: 2395-2403, 2013.

9. Dehghan A, Dupuis J, Barbalic M, et al: Meta-analysis of genome-wide association studies in $>80000$ subjects identifies multiple loci for C-reactive protein levels. Circulation 123: 731-738, 2011.

10. Retterstol L, Eikvar L and Berg K: A twin study of C-Reactive protein compared to other risk factors for coronary heart disease. Atherosclerosis 169: 279-282, 2003.

11. de Beer FC, Soutar AK, Baltz ML, Trayner IM, Feinstein A and Pepys MB: Low density lipoprotein and very low density lipoprotein are selectively bound by aggregated $\mathrm{C}$-reactive protein. J Exp Med 156: 230-242, 1982.

12. Zhang YX, Cliff WJ, Schoefl GI and Higgins G: Coronary C-reactive protein distribution: its relation to development of atherosclerosis. Atherosclerosis 145: 375-379, 1999.

13. Morita A, Nakayama T, Doba N, Hinohara S and Soma M: Polymorphism of the C-reactive protein (CRP) gene is related to serum CRP level and arterial pulse wave velocity in healthy elderly japanese. Hypertens Res 29: 323-331, 2006.

14. Kathiresan S, Larson MG, Vasan RS, et al: Contribution of clinical correlates and $13 \mathrm{C}$-reactive protein gene polymorphisms to interindividual variability in serum C-reactive protein level. Circulation 113: 1415-1423, 2006.

15. Suk HJ, Ridker PM, Cook NR and Zee RY: Relation of polymorphism within the C-reactive protein gene and plasma CRP levels. Atherosclerosis 178: 139-145, 2005.
16. Brull DJ, Serrano N, Zito F, et al: Human CRP gene polymorphism influences CRP levels: implications for the prediction and pathogenesis of coronary heart disease. Arterioscler Thromb Vasc Biol 23: 2063-2069, 2003.

17. Gabriel S, Ziaugra L and Tabbaa D: SNP genotyping using the sequenom MassARRAY iPLEX platform. Curr Protoc Hum Genet 2: 212, 2009.

18. Excoffier L and Lischer HE: Arlequin suite ver 3.5: a new series of programs to perform population genetics analyses under linux and windows. Mol Ecol Resour 10: 564-567, 2010.

19. Sham PC and Curtis D: Monte carlo tests for associations between disease and alleles at highly polymorphic loci. Ann Hum Genet 59: 97-105, 1995.

20. Dupont WD and Plummer WD Jr: Power and sample size calculations. A review and computer program. Control Clin Trials 11: $116-128,1990$.

21. Tangurek B, Ozer N, Sayar N, et al: The relationship between endothelial nitric oxide synthase gene polymorphism (T-786 C) and coronary artery disease in the turkish population. Heart Vessels 21: 285-290, 2006.

22. Jaffe AS, Ravkilde J, Roberts R, et al: It's time for a change to a troponin standard. Circulation 102: 1216-1220, 2000.

23. Freund Y, Chenevier-Gobeaux C, Bonnet P, et al: High-sensitivity versus conventional troponin in the emergency department for the diagnosis of acute myocardial infarction. Crit Care 15: R147, 2011.

24. Liuzzo G, Biasucci LM, Gallimore JR, et al: The prognostic value of $\mathrm{C}$-reactive protein and serum amyloid a protein in severe unstable angina. N Engl J Med 331: 417-424, 1994.

25. Berk BC, Weintraub WS and Alexander RW: Elevation of C-reactive protein in 'active' coronary artery disease. Am J Cardiol 65: 168-172, 1990.

26. Zebrack JS, Muhlestein JB, Horne BD and Anderson JL; Intermountain Heart Collaboration Study Group: C-reactive protein and angiographic coronary artery disease: independent and additive predictors of risk in subjects with angina. J Am Coll Cardiol 39: 632-637, 2002.

27. Koenig W, Sund M, Frohlich M, et al: C-reactive protein, a sensitive marker of inflammation, predicts future risk of coronary heart disease in initially healthy middle-aged men: results from the MONICA (Monitoring Trends and Determinants in Cardiovascular Disease) augsburg cohort study, 1984 to 1992. Circulation 99: 237-242, 1999.

28. Garcia-Moll X, Zouridakis E, Cole D and Kaski JC: C-reactive protein in patients with chronic stable angina: differences in baseline serum concentration between women and men. Eur Heart J 21: 1598-1606, 2000.

29. Balistreri CR, Vasto S, Listi F, et al: Association between $+1059 \mathrm{G} / \mathrm{C}$ CRP polymorphism and acute myocardial infarction in a cohort of patients from sicily: a pilot study. Ann N Y Acad Sci 1067: 276-281, 2006.

30. van der Meer MG, Cramer MJ, van der Graaf Y, Doevendans PA and Nathoe HM; (on behalf of the SMART study group): Gender difference in long-term prognosis among patients with cardiovascular disease. Eur J Prev Cardiol 21: 81-89, 2014. 